Supplement of Biogeosciences, 15, 5831-5845, 2018

https://doi.org/10.5194/bg-15-5831-2018-supplement

(C) Author(s) 2018. This work is distributed under

the Creative Commons Attribution 4.0 License.

(c) (1)

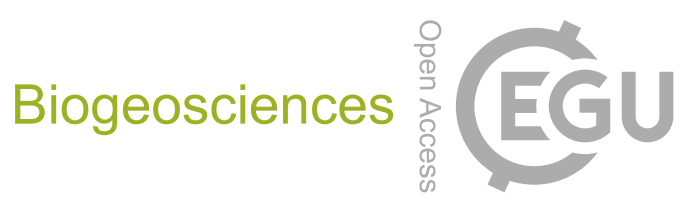

Supplement of

\title{
Quantification of lignin oxidation products as vegetation biomarkers in speleothems and cave drip water
}

Inken Heidke et al.

Correspondence to: Thorsten Hoffmann (t.hoffmann@uni-mainz.de)

The copyright of individual parts of the supplement might differ from the CC BY 4.0 License. 


\title{
Supplement to "Quantification of lignin oxidation products as vegetation biomarkers in speleothems"
}

\author{
I. Heidke, D. Scholz, T. Hoffmann
}

S1 Evaporation effects of different elution solvents for SPE
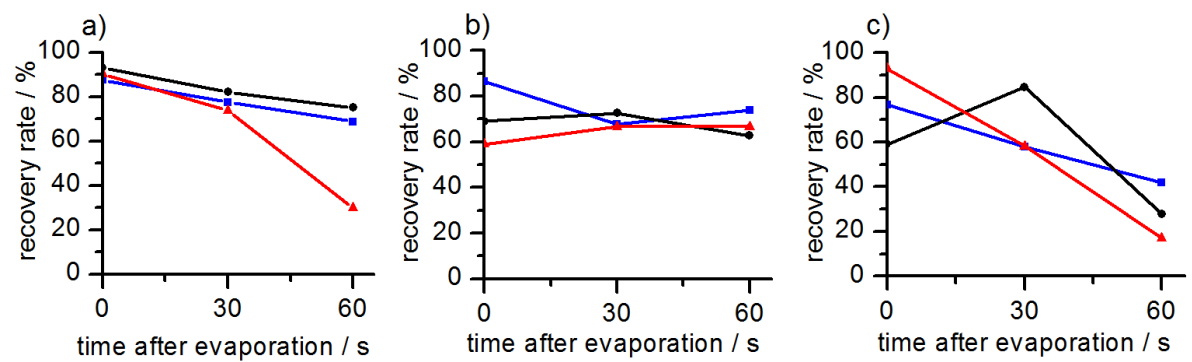

Figure S1. Recovery rates of vanillin after evaporation in a) acetonitrile, b) methanol and c) ethyl acetate at $45^{\circ} \mathrm{C}$ (red triangles), $30{ }^{\circ} \mathrm{C}(\mathrm{black}$ circles) and $25{ }^{\circ} \mathrm{C}$ (blue squares). The residue was re-dissolved in $\mathrm{H}_{2} \mathrm{O} / \mathrm{ACN}$ 9:1 (v/v) and analyzed. At elevated evaporation temperatures, vanillin and other aldehydes evaporated and were lost for analysis. In ethyl acetate, this evaporative loss was more pronounced than in acetonitrile and methanol. 


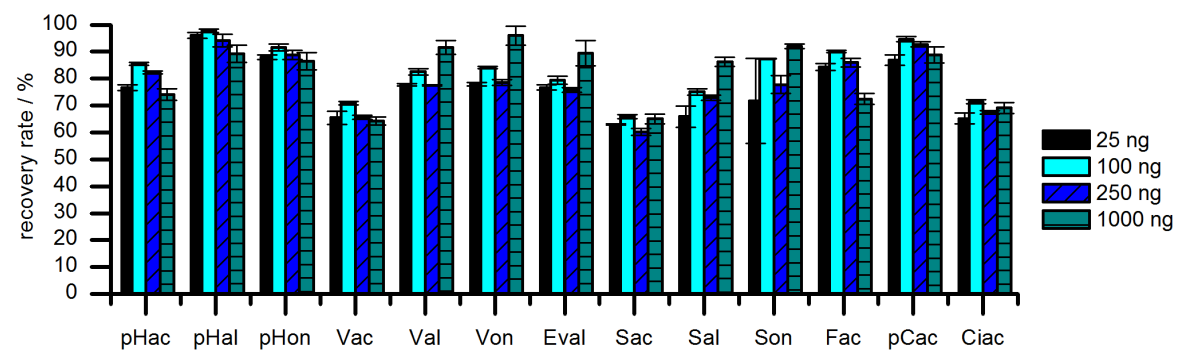

Figure S2. Recovery rates of the solid phase extraction of LOPs at different spiking concentrations. $20 \mathrm{~mL}$ of a surrogate sample solution ( $2 \mathrm{~mol} \cdot \mathrm{L}^{-1} \mathrm{NaCl}$ in ultrapure water, acidified with $\mathrm{HCl}$ to $\mathrm{pH}$ 2) were spiked with 25, 100, 250 and $1000 \mathrm{ng}$ of LOP standards.
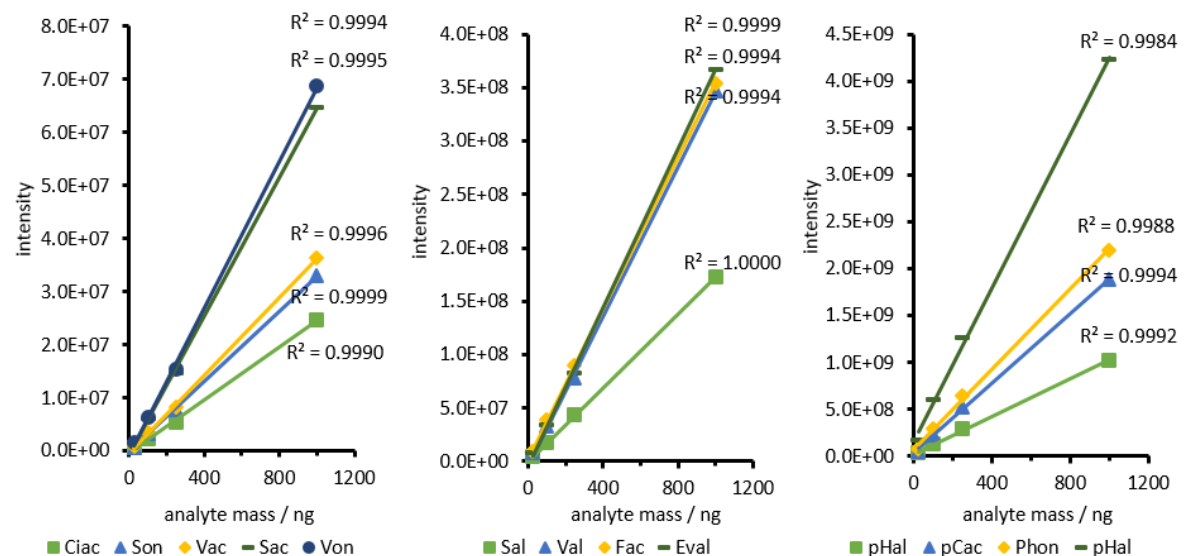

Figure S3. Linearity test of the SPE method for the extraction of LOPs. $20 \mathrm{~mL}$ of a surrogate sample solution $\left(2 \mathrm{~mol} \cdot \mathrm{L}^{-1} \mathrm{NaCl}\right.$ in ultrapure water, acidified with $\mathrm{HCl}$ to $\mathrm{pH} 2$ ) were spiked with $25,100,250$ and $1000 \mathrm{ng}$ of LOP standards. 


\section{S3 Test of the addition of glucose to prevent overoxidation}

Many studies (e.g., Kaiser and Benner, 2012; Louchouarn et al., 2000; Spencer et al., 2010) recommended to add glucose to samples with low organic carbon content to prevent overoxidation of aldehydes. As stalagmite samples do have a low organic carbon content compared to soil or sediment samples, we tested the addition of glucose. The result was that the ratio of Vac/Val

5 did indeed decrease from $0.48 \pm 0.11$ without glucose to $0.26 \pm 0.12$ with glucose, because the yield of vanillin increased with the addition of glucose. Nevertheless, the ratio of $\mathrm{C} / \mathrm{V}$ decreased from $0.46 \pm 0.12$ to $0.26 \pm 0.31$ and the ratio of $\mathrm{S} / \mathrm{V}$ decreased from $0.76 \pm 0.19$ to $0.41 \pm 0.36$ (Fig. S4). This means that the addition of glucose did not prevent cinnamyl and syringyl phenols from overoxidation. In contrast, there were more interfering peaks in the chromatograms with glucose (Fig. S5), which made integration difficult and lead to increased uncertainty in quantification. Consequently, no glucose was added in the $\mathrm{CuO}$ oxidation step.

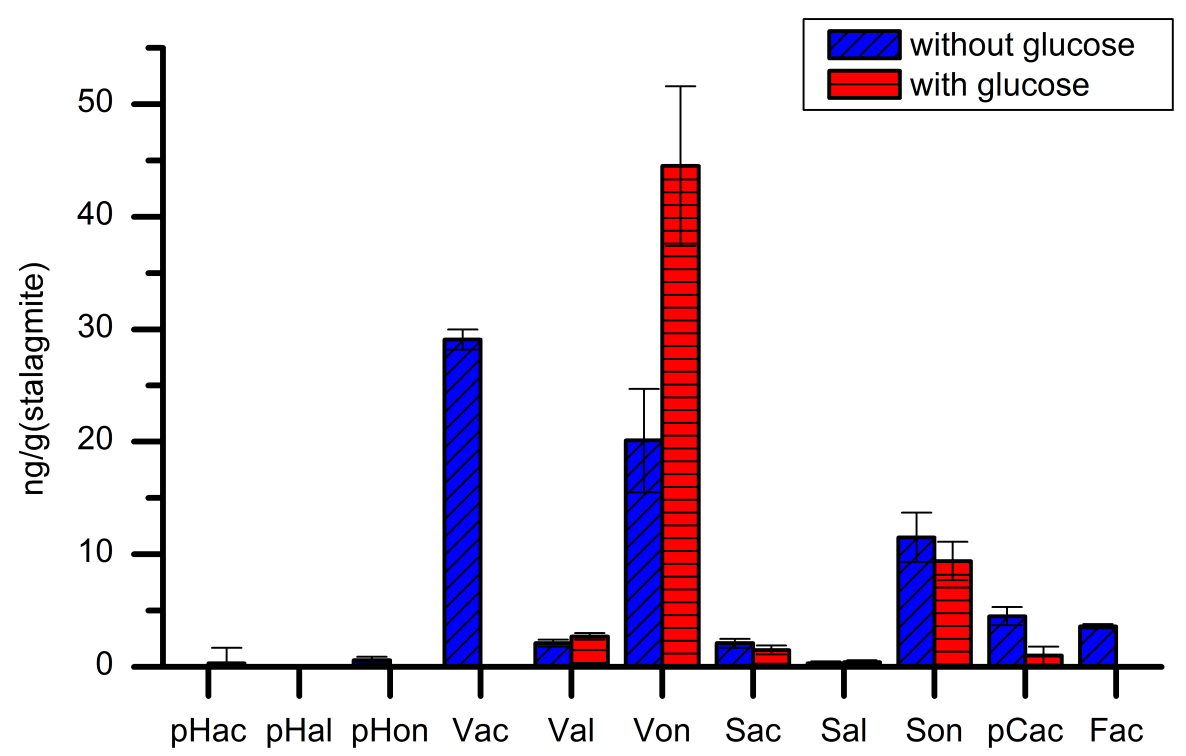

Figure S4. Comparison of LOP concentrations with and without the addition of glucose. Only for Von, there was an increase in the concentration with the addition of glucose. For all other analytes, the method without glucose gave better results. 


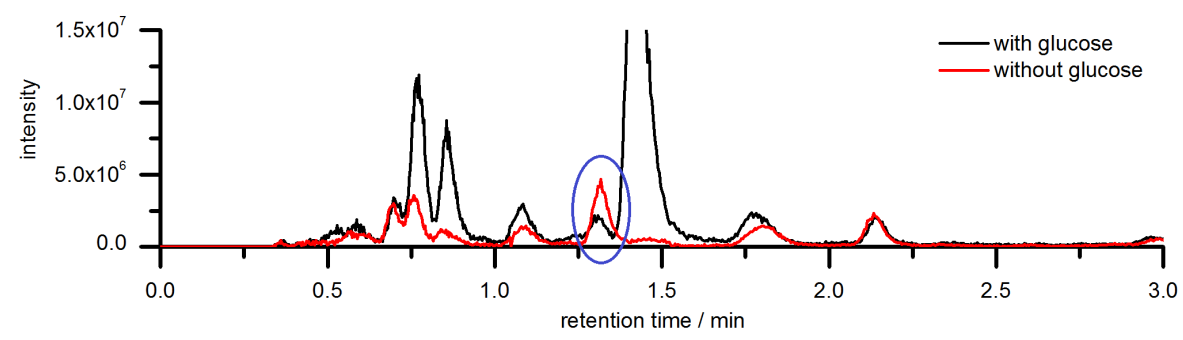

Figure S5. Chromatogram of $\mathrm{m} / \mathrm{z} 167.03498$ (vanillic acid) with (black line) and without (red line) the addition of glucose. The peak of vanillic acid is circled. It was higher and better separated from neighbouring peaks without the addition of glucose. Similar observations were made for other analytes, too.

\section{S4 Linear regresssion parameters of the external calibration functions and instrumental limits of detection (LOD) and qualibration (LOQ).}

Table S1. Linear regresssion parameters of the external calibration functions and instrumental limits of detection (LOD) and qualibration (LOQ).

\begin{tabular}{lrrrrr}
\hline analyte & $\mathrm{R}^{2}$ & slope & intersept & $\begin{array}{r}\text { instrumental LOD / } \\
\mathrm{ng} \cdot \mathrm{mL}^{-1}\end{array}$ & $\begin{array}{r}\text { instrumental LOQ / } \\
\mathrm{ng} \cdot \mathrm{mL}^{-1}\end{array}$ \\
\hline $\mathrm{pHac}$ & 0.9998 & 6371269 & 229351 & 0.39 & 1.19 \\
$\mathrm{pHal}$ & 0.9949 & 24875695 & 10116687 & 0.05 & 0.15 \\
$\mathrm{pHon}$ & 0.9988 & 14313979 & 1679485 & 0.18 & 0.55 \\
Vac & 0.9998 & 206028 & 3287 & 0.48 & 1.46 \\
Val & 0.9997 & 630114 & 39639 & 0.25 & 0.75 \\
Von & 0.9962 & 129627 & -6652 & 2.27 & 6.89 \\
Sac & 0.9993 & 270474 & -23398 & 0.55 & 1.66 \\
Sal & 0.9996 & 170558 & -17658 & 3.75 & 11.36 \\
Son & 0.9998 & 122729 & 3837 & 7.92 & 24.00 \\
pCac & 0.9978 & 11971947 & 2189589 & 1.08 & 3.26 \\
Fac & 0.9998 & 2028750 & -169451 & 0.10 & 0.29 \\
Eval & 0.9998 & 1769186 & 929 & 0.24 & 0.73 \\
Ciac & 0.9996 & 100371 & 7569 & 4.44 & 13.45 \\
\hline
\end{tabular}




\section{S5 Equations used for calculation of concentrations, lignin oxidation parameters and errors bars}

The concentration $c$ (analyte) of real samples was calculated by equation (1), with $A=$ mean peak area of three LC-MS analyses of the sample, $B=$ mean peak area of three LC-MS analyses of the blank sample, $b=$ intersect of the Y-axis of the external calibration curve, $m=$ slope of the external calibration curve, $f_{r}=$ recovery factor of the internal standard ethylvanillin (Eval),

5 see equation (2), $V=$ volume of the final sample solution and $m_{\text {sample }}=$ sample mass.

$c($ analyte $)=\frac{A-B-b}{m} \cdot \frac{1}{f_{r}} \cdot \frac{V}{m_{\text {sample }}}$

$f_{r}=\frac{c(\text { Eval })_{\text {measured }}}{c(\text { Eval })_{\text {spiked }}}$

The error $\Delta c$ (analyte) of the concentration $c$ (analyte) was calculated by equation (3).

$\Delta c($ analyte $)=\sqrt{\left(\frac{\partial A}{\partial c} \Delta A\right)^{2}+\left(\frac{\partial B}{\partial c} \Delta B\right)^{2}+\left(\frac{\partial b}{\partial c} \Delta b\right)^{2}+\left(\frac{\partial m}{\partial c} \Delta m\right)^{2}+\left(\frac{\partial f_{r}}{\partial c} \Delta f_{r}\right)^{2}+\left(\frac{\partial m_{\text {sample }}}{\partial c} \Delta m_{\text {sample }}\right)^{2}}$

The lignin oxidation parameters were calculated according to equations (4) to (9). Their errors were calculated using the law of propagation of uncertainty (equations not shown).

C-group LOPs $=c(\mathrm{p}-\mathrm{Cac})+c(\mathrm{t}-\mathrm{Fac})$

$\mathrm{S}$-group LOPs $=c(\mathrm{Sac})+c(\mathrm{Sal})+c(\mathrm{Son})$

V-group LOPs $=c(\mathrm{Vac})+c(\mathrm{Val})+c(\mathrm{Von})$

$15 \Sigma 8=\mathrm{C}$-group LOPs $+\mathrm{S}$-group LOPs + V-group LOPs

$\mathrm{C} / \mathrm{V}=\frac{\mathrm{C} \text {-group LOPs }}{\text { V-group LOPs }}$

$\mathrm{S} / \mathrm{V}=\frac{\text { S-group LOPs }}{\text { V-group LOPs }}$ 


\section{References}

Kaiser, K. and Benner, R.: Characterization of Lignin by Gas Chromatography and Mass Spectrometry Using a Simplified CuO Oxidation Method, Analytical chemistry, 84, 459-464, 2012.

Louchouarn, P., Opsahl, S., and Benner, R.: Isolation and Quantification of Dissolved Lignin from Natural Waters Using Solid-Phase Extraction and GC/MS, Analytical chemistry, 72, 2780-2787, 2000.

Spencer, R. G. M., Hernes, P. J., Ruf, R., Baker, A., Dyda, R. Y., Stubbins, A., and Six, J.: Temporal controls on dissolved organic matter and lignin biogeochemistry in a pristine tropical river, Democratic Republic of Congo, Journal of Geophysical Research, $115,2010$. 